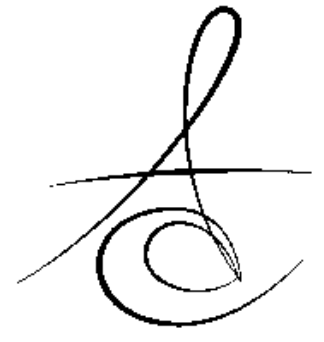

Prof. Dr. Funda BAYINDIR*

\section{BİR VE İKİ Bi̇LEŞENDEN OLUŞAN GEÇİi̇ SİMANLARIN DENTİNE BAĞLANMA DAYANIMLARININ KARŞILAŞTIRLMASI ${ }^{\sharp}$}

\section{COMPARISON OF SHEAR BOND STRENGTH OF ONE \& TWO COMPONENT PROVISIONAL CEMENTS TO HUMAN DENTINE ${ }^{*}$}

\author{
Dr. Engin Volkan DİKEÇ*
}

Makale Kodu/Article code: 2474

Makale Gönderilme tarihi: 30.11 .2015

Kabul Tarihi: 14.12 .2015

\section{öz}

Amaç: Bu çalışmada bir ve iki bileşenden oluşan geçici simanların dentine bağlanma dayanımlarını karşılaştırmak amaçlanmıştır.

Gereç ve Yöntem: Bu çalışma kapsamında; 40 adet çekilmiş üçüncü büyük azı dişi, 3 farklı iki bileşenli (Temp-Bond NE, Life Regular Set, Dycal), 1 adet tek bileşenli (PreVISION CEM) geçici siman ve 1 adet selfcure kompozit rezin kullanıldı. 40 adet kompozit örnek rastgele 4 gruba ayrıldı ve 4 farklı geçici siman ile çekilmiş dişlerin dentin yüzeyine simante edildi. Simantasyondan 1 gün sonra, universal test cihazı ile örneklere bağlanma dayanım testi uygulandı. Verilerin istatistiksel analizi tek yönlü varyans analizi ve Tukey çoklu karşılaştırma testleri kullanılarak yapıldı.

Bulgular: Tek yönlü varyans analizi verilerine göre, farklı geçici simanların dentine bağlanmasında istatistiksel bakımdan önemli derecede fark vardır $(p<0.001)$. Ortalama bağlanma dayanım değerleri ise 0.17 MPa Life Regular Set, 0.43 MPa Dycal, 0.54 MPa PreVISION CEM, 0.77 MPa Temp Bond NE şeklindedir. Sonuçlar: Elde edilen veriler ışı̆̆ında, tek bileşenli geçici simanların iki bileşenli simanlar kadar dentine bağlanma dayanıma sahip olduğu gözlenmiştir.

Anahtar Kelimeler: Geçici siman, dentin, kompozit.

\section{ABSTRACT}

Aim: The aim of this study was to evaluate the shear bond strength of one and two component temporary cements to human dentine.

Material and Methods: In this study, 40 extracted third human molars, three different two component provisional cements (Temp-Bond NE, Life Regular Set, Dycal), one component provisional cement (PreVISION CEM) and one self-curing composite material were used. 40 composite specimens were divided four groups randomly and bonded with four provisional cements to human dentine. After a day, the shear bond strength test was applied by a universal testing machine to specimens. The statistically analysis of obtained data were performed with use one-way analysis of variance and Tukey's multiple comparison test.

Results: The result of one-way analysis of variance test showed that there were statically significant differences between bond strength of different provisional cements to dentine $(p<0.001)$. The mean shear bond values that $0.17 \mathrm{MPa}$ Life Regular Set, $0.43 \mathrm{MPa}$ Dycal, 0.54 MPa PreVISION CEM, 0.77 MPa Temp Bond NE.

Conclusions: The obtained data presented that the one component provisional cement affected the bond strength to human dentine as two component provisional cements.

Key Words: Temporary cement, human dentine, composite.

\footnotetext{
*Atatürk Üniversitesi Diş Hekimliği Fakültesi Protetik Diş Tedavisi AD.

F 12-15 Kasım 2015 tarihinde Antalya, Türkiye'de düzenlenen 22. Uluslararası Türk Prostodonti ve İmplantoloji Derneği Bilimsel Kongresinde sunulmuştur
} 


\section{GİRIŞ}

Sabit protezlerin hastaya teslimi aşamasında, estetik ve biyolojik uyumunu iyi değerlendirmek ve maksimum hasta konforunu sağlamak amacıyla geçici simantasyon büyük önem taşımaktadır. Geçici yapıştırma materyalleri ayrıca hataların değerlendirilebilmesi, diş hassasiyetinin en aza indirilmesi, diş hareketliliğinin önlenmesi ve implant üstü protezlerde söküm kolaylığından dolayı daimi simantasyon yerine kullanılabilmektedir. Bununla birlikte klinikte bazı durumlarda geçici restorasyonların uzun süre geçici olarak simante edilmesi söz konusu olabilir. ${ }^{1}$

Geçici simantasyonun avantajları kadar dezavantajları da bulunmaktadır. Dişe tutunması daimi simanlara göre daha zayıf olduğu için protezler daha kolay desimante olmakta ve seanslar arası süre kısalabilmektedir.

İdeal bir geçici simandan dentin yüzeyine kuvvetli bağlanabilmesi, dentin hassasiyetini en aza indirebilmesi, uzun süre ağızda kalabilmesi ve ağız sıvılarını dişe iletmemesi, hazırlanma ve kullanım kolaylığına sahip olması beklenmektedir.

Diş hekimliği kliniklerinde rutin olarak öjenol içeren, öjenol içermeyen ve kalsiyum hidroksit esaslı geçici simanlar kullanılmaktadır. Geçici ve daimi kuronların geçici simantasyonlarında öjenol içeren geçici simanlar yaygın olarak kullanılmaktadır. ${ }^{2}$ Öjenol içerikli simanlar diş hasssasiyetini azaltmasına rağmen kompozit rezin ile etkileşime girebilmekte ve polimerizasyonu olumsuz yönde etkilemektedir. ${ }^{3-5}$

Öjenol içermeyen simanlar ise sedatif etkisi olmamasına rağmen dentin yüzeylerinden kolay temizlenebilmesi ve kuvvetli bağlanabilmesi gibi özelliklere sahiptir.

Kalsiyum hidroksit esaslı geçici simanlar, sedatif etki göstermekle birlikte yapısında öjenol ihtiva etmediğinden dolayı rezin simanların polimerizasyonu açısından öjenol içerikli simanlara göre daha güvenilirdirler.

Klinikte kullanılmakta olan geçici simanlar genellikle baz ve katalizör olmak üzere iki bileşenden oluşmakta ve iki ayrı tüp şeklinde üretilmektedir. Üretici firmalar uygulama kolaylığı kazandırma amacıyla baz ve katalizörü tek tüp altında toplayarak yeni geçici simanlar üretmeye başlamışlardır.

Bu çalışmamızda, bir ve iki bileşenden oluşan ve farklı kimyasal yapılara sahip geçici simanların dentine bağlanma dayanımlarının karşılaştırılması amaçlanmıştır. Hipotezimiz ise, tek bileşenden oluşan geçici simanın iki bileşenli simanlarınkine benzer bir bağlanma dayanımı göstereceğidir.

\section{GEREÇ VE YÖNTEM}

Çalışma kapsamında toplam 40 adet çekilmiş üçüncü büyük azı dişi kullanıldı. Çalışmada çürük intiva etmeyen, kuron harabiyeti olmayan, periodontal nedenlerden ötürü çekilmiş olan dişler toplanıp kullanıldı. Çekilen dişler kullanıma kadar $4^{\circ} \mathrm{C}$ 'de distile su içerisinde bekletildi.

Dişlerin oklüzal yüzeyindeki mine su soğutmalı piyasemen (NSK Ti-Max X20, NSK Japonya) ile horizantal bir şekilde uzaklaştırıldı. Daha sonra dişler silindirik bir kalıbın içerisinde $(15 \mathrm{~mm}$ çap, $20 \mathrm{~mm}$ yükseklikte) tavanı dişin horizontal kesiti olacak şekilde kendiliğinden sertleşen akrilik rezin içine (Vertex Self Curing, Vertex Dental, Dentimex, Hollanda) gömüldü.

$4 \mathrm{~mm}$ çap ve $4 \mathrm{~mm}$ yükseklikte silindir şeklinde 40 adet kompozit (Structure $2 \mathrm{SC}$ VOCO GmbH, Cuxhaven, Almanya) örnek silikon kalıp içerisinde hazırlandı (Şekil 1). Bu 40 adet kompozit örnek simantasyon için rastgele 4 gruba ayrıldı.

Simantasyon işlemi için, 3 farklı iki bileşenli Temp-Bond NE (Kerr Corporation, ABD), Life Regular Set (Kerr Corporation, ABD), Dycal (Dentsply, Kanada), 1 adet tek bileşenli PreVISION CEM (Heraus Kulzer, Hanau, Almanya) geçici siman kullanıldı (Şekil 2). Seçilen geçici simanlardan Temp-Bond NE ile PreVISION CEM yapısında öjenol içermezken; Life Regular Set ve Dycal yapısında kalsiyum hidroksit içermektedir.

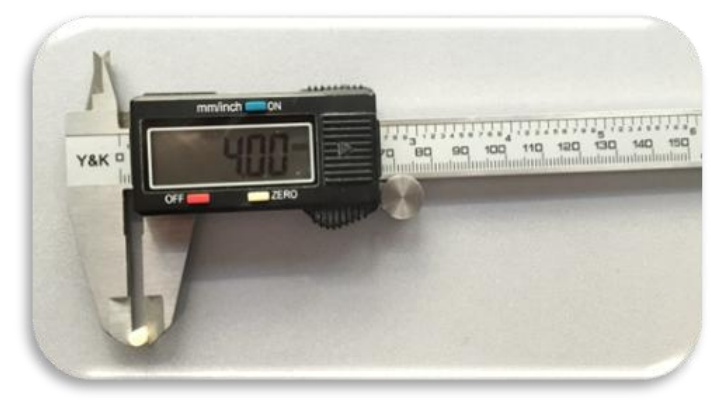

Şekil 1. Silindirik yapıdaki kompozit örnek 


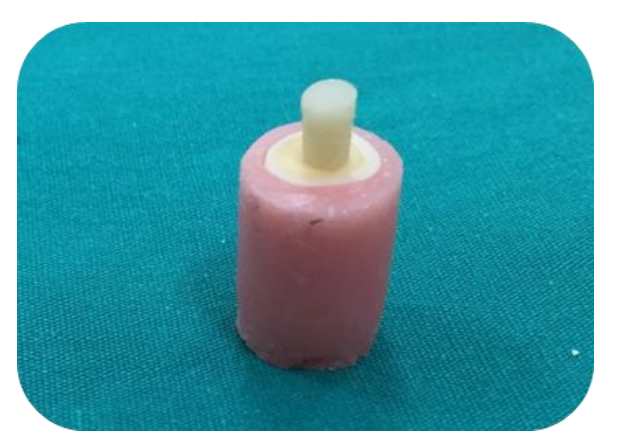

Şekil 2. Kompozit-dentin siman bağlantısı

Her bir geçici simanla 10'ar adet kompozit örnek dentin yüzeylerine simante edildi. Standardizasyonu sağlamak amacıyla simantasyon işlemi tek bir araştırmacı tarafından yapılıp parmak basıncı uygulandı. Simantasyon işleminden 1 gün sonra universal test cihazı (Model 2519-106; Instron Corp., ABD) ile örneklere bağlanma dayanım testi uygulandı (Şekil 3).

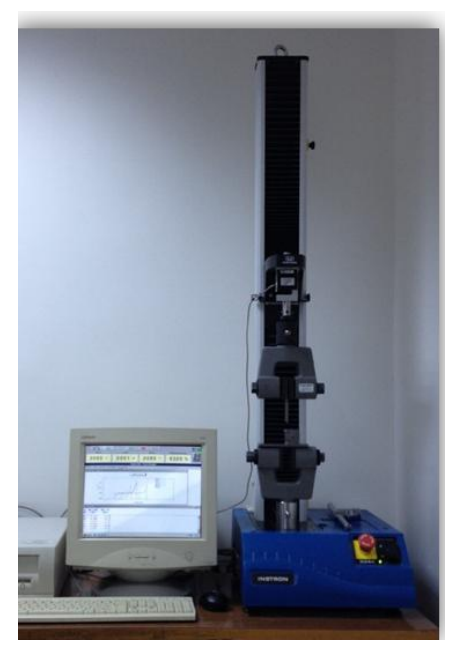

Şekil 3. Bağlanma dayanımı testi

Bağlanma dayanımı değerlerinin siman grupları arasında karşılaştırıması için tek yönlü varyans analizi kullanıldı. Gruplar arası çoklu karşılaştırmalar için Tukey testi kullanıldı.

\section{BULGULAR}

Tek yönlü varyans analizi verilerine göre, farklı geçici simanların dentine bağlanmasında istatistiksel bakımdan önemli derecede fark vardır $(p<0.001)$.

Siman gruplarına ait ortalama değerler ve standart sapma değerleri Tablo 1'de ve ayrıca gruplara ait ortalama değerler Grafik 1'de gösterilmiştir. Bu tabloya göre en yüksek bağlanma dayanımı değeri 0,77 MPa ile Temp-Bond NE grubunda bulunurken en düşük bağlanma dayanımı değeri 0,17 MPa ile Life Regular Set grubunda bulunmuştur.

Tablo 1. Gruplara ait ortalama bağlanma dayanımı değerleri

\begin{tabular}{|c|c|c|c|c|}
\hline & Ortalama & $\begin{array}{c}\text { Standart } \\
\text { Sapma }\end{array}$ & Min & Max \\
\hline $\begin{array}{c}\text { Life } \\
\text { Regular } \\
\text { Set }\end{array}$ &, 17 &, 18 &, 02 &, 62 \\
\hline $\begin{array}{c}\text { Temp- } \\
\text { Bond NE }\end{array}$ &, 77 &, 23 &, 49 & 1,08 \\
\hline Dycal &, 43 &, 20 &, 14 &, 71 \\
\hline $\begin{array}{c}\text { PreVISION } \\
\text { CEM }\end{array}$ &, 54 &, 26 &, 23 & 1,06 \\
\hline Toplam &, 48 &, 30 &, 02 & 1,08 \\
\hline
\end{tabular}

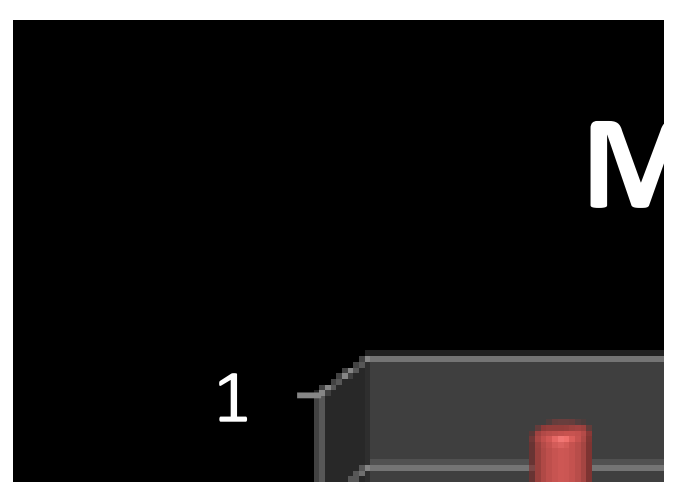

Grafik 1. Simanlara ait ortalama bağlanma dayanımı değerleri

Gruplara ait bağlanma dayanımı değerleri istatistiksel olarak değerlendirilmiş olup ikili karşılaştırmaları Tablo 2' de gösterilmiştir.

Bu tabloya göre, hem Life Regular Set grubu ile Temp-Bond NE ve PreVISION CEM grubu arasında hem de Temp-Bond NE grubuyla Dycal grubu arasında istatistiksel olarak anlamlı farklılık bulunmaktadır $(p<0,05)$.

Bununla birlikte, PreVISION CEM grubu ile Temp-Bond NE ile Dycal grupları arasında ve Dycal grubuyla Life Regular Set grubu arasında istatistiksel olarak anlamlı bir farklılık bulunmamaktadır ( $p>0,05)$.

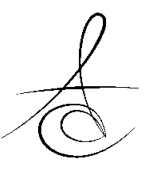


Atatürk Üniv. Diş Hek. Fak. Derg.

J Dent Fac Atatürk Uni

Cilt:26, Sayı:1, Yıl: 2016, Sayfa: 87-91

Tablo 2. Gruplar arası istatistiksel değerlendirme

\begin{tabular}{|l|c|c|c|c|}
\hline & $\begin{array}{c}\text { Life } \\
\text { Regular } \\
\text { Set }\end{array}$ & $\begin{array}{c}\text { Temp- } \\
\text { Bond } \\
\text { NE }\end{array}$ & Dycal & $\begin{array}{c}\text { PreVISION } \\
\text { CEM }\end{array}$ \\
\hline $\begin{array}{l}\text { Life } \\
\text { Regular } \\
\text { Set }\end{array}$ & $\mathrm{X}$ & & & \\
\hline $\begin{array}{l}\text { Temp- } \\
\text { Bond NE }\end{array}$ &, $00 *^{*}$ & $\mathrm{X}$ & & \\
\hline Dycal &, 061 &, $009 *$ & $\mathrm{X}$ & \\
\hline $\begin{array}{l}\text { PreVISION } \\
\text { CEM }\end{array}$ &, $\mathbf{0 0 3 *}$ &, 129 &, 661 & $\mathrm{X}$ \\
\hline
\end{tabular}

$*_{p}<0,05$ istatistiksel olarak anlamlı kabul edildi

\section{TARTIŞMA}

Geçici simanlar, geçici kuronların simantasyonunda kullanılabildiği gibi, daimi protezlerin uzun veya kısa dönem takibi için geçici simantasyonda da kullanılabilmektedir. $\mathrm{Bu}$ nedenden dolayı ideal bir geçici simanın dentinle iyi bir bağlantı yapabilmesi ve uzun dönem mekanik ve kimyasal özelliklerini koruması gerekmektedir.

Geçici simanlar piyasada genellikle öjenol içeren ve içermeyen simanlar şeklinde bulunmaktadır. Öjenol içerikli simanlar dentin hassasiyetinin aşırı olduğu durumlarda pulpayı korumak, sedatif etki yapmak $^{6-9}$ ve hasta şikâyetlerini en aza indirmek için kullanılmaktadır. Ancak öjenol içeren simanların kompozit rezinlerin polimerizasyonunu olumsuz etkilemesi ve diş yapısından kolay temizlenememesi gibi sorunları mevcuttur. Bu nedenlere bağlı olarak çalışmamızda iki adet öjenol içermeyen ve iki adet de kalsiyum hidroksit esaslı geçici siman kullanılmıştır.

Literatürde öjenol içeren geçici simanlarla yapılmış çalışmalar mevcuttur. ${ }^{10-15}$ Yap ve ark. ${ }^{9}$ öjenol içerikli geçici simanların kompozit rezinlerin dentine bağlanma dayanımını önemli derecede azalttığını belirtmişlerdir.

Olin ve ark. ${ }^{16}$ yaptıkları bir çalışmada öjenol içermeyen geçici simanların öjenol içerenlere göre daha yüksek bağlanma dayanım değerlerine sahip olduğunu rapor etmişlerdir.

Lepe ve ark. ${ }^{17} 2$ adet geçici materyal ve 4 adet de geçici siman kullanarak yaptıkları bir çalışmanın sonucunda, 24 saat sonra yapılan ölçümde en yüksek bağlanma dayanımı değerini öjenol içerikli Temp-Bond ile simante edilen geçici kuronlarda 0.7 MPa olarak bulmuşlardır. Bu çalışmamızın sonucunda da en yüksek bağlanma dayanımı değeri 0.77 MPa ile öjenol
BAYINDIR, ÖZDOĞAN, DİKEÇ

içermeyen Temp Bond NE grubunda bulunmuştur.

Kim ve ark. ${ }^{18}$ Temp-Bond NE geçici simanın kuron retansiyonunun öjenol içerikli simanlardan daha yüksek olduğunu bulmuşlardır. Ishikiriama ve ark. ${ }^{19}$ kalsiyum hidroksit esaslı geçici simanlarla yaptıkları çalışmalarında, en yüksek retansiyon değerlerini Dycal ile simante edilen gruplarda bulmuşlardır, yine de bu değer Temp Bond geçici simanlara göre çok düşük bir değerdir.

Çalışma sonucunda elde edilen değerlere göre de öjenol içermeyen geçici simanlar dentine daha sıkı bağlanırken, kalsiyum hidroksit içeren geçici simanlar daha az bağlanma dayanımı göstermiştir.

Dental materyallerdeki gelişmelere bağlı olarak piyasaya yeni malzemeler sunulmakta ve hem kullanım kolaylığı hem de üstün mekanik özelliklere sahip materyaller hekimler tarafından tercih edilmektedir. Tek bileşenli yapıya sahip olan ve karıştırma işlemi olmadan baz ile katalizörünü bir arada içeren geçici simanlar doğrudan protez içerisine uygulanabilmekte ve zaman tasarrufu sağlamaktadır. Literatürde bu tür simanların dentine bağlanma dayanımı ile ilgili çalışmalar bulunmamaktadır. Ancak çalışmamız sonucunda elde ettiğimiz verilere göre; tek bileşenden oluşan PreVISION CEM geçici siman Life Regular Set ve Dycal'dan daha yüksek bir bağlanma dayanımına sahipken Temp-Bond NE'nin gerisinde kalmıştır. Fakat bu farklılık istatistiksel bakımdan önemli olmadığı için ( $p>0.05$ ) başlangıçta kurmuş olduğumuz hipotezimiz kabul edilmiştir.

\section{SONUÇ}

Bu çalışmanın sonuçlarına göre; öjenolsüz tek bileşenli geçici simanların da iki bileşenli simanlar kadar dentine bağlanma dayanımında başarılı olduğu fakat bu konuyla ilgili daha fazla çalışma yapılması gerektiği, öjenol içermeyen simanların kalsiyum hidroksit içeren simanlara göre dentine daha kuvvetli bağlandığı görülmüştür.

\section{KAYNAKLAR}

1.Lewinstein I, Chweidan $\mathrm{H}$, Matalon S, Pilo R. Retention and marginal leakage of provisional crowns cemented with provisional cements enriched with chlorhexidine diacetate. J Prosthet Dent 2007, 98: 373-8. 
2.Dinckal N. Cements, Atatürk Univ. Dis Hek Fak Derg 1993; 3 2: 57-62.

3.Phillips RW. Skinner's science of dental materials. 8th ed, W.B. Saunders, Philadelphia. 1982 pp 489.

4.Grajower R, Hirschfeld Z, Zalkind M. Compatibility of a composite resin with pulp insulating materials. A scanning electron microscope study. J Prosthet Dent1974, 32: 70-7.

5.Grajower R, Hirschfeld Z, Zalkind M. Observations on cavity liners for composite resin restorations. J Prosthet Dent1976, 36: 265-73.

6.Abo-Hamar SE, Federlin $M$, Hiller $K A$, Friedl $\mathrm{KH}$, Schmalz G. Effect of temporary cements on the bond strength of ceramic luted to dentin. Dent Mater 2005, 21: 794-803.

7.Camps J, About I, Gouirand S, Franquin JC. Dentin permeability and eugenol diffusion after full crown preparation. Am J Dent2003, 16: 112-6.

8.Paul SJ, Scharer P. Post and core reconstruction for fixed prosthodontic restoration. Pract Periodontics Aesthet Dent1997, 9: 513-20; quiz 522.

9.Yap AU, Shah KC, Loh ET, Sim SS, Tan CC. Influence of eugenol-containing temporary restorations on bond strength of composite to dentin. Oper Dent2001, 26: 556-61.

10. Millstein PL, Nathanson D. Effects of temporary cementation on permanent cement retention to composite resin cores. J Prosthet Dent1992, 67: 856-9.

11. Combe EC, Shaglouf AM, Watts DC, Wilson NH. Mechanical properties of direct core build-up materials. Dent Mater 1999, 15: 158-65.

12.Jung M, Ganss C, Senger S. Effect of eugenolcontaining temporary cements on bond strength of composite to enamel. Oper Dent1998, 23: 63-8.

13.Ganss C, Jung M. Effect of eugenol-containing temporary cements on bond strength of composite to dentin. Oper Dent1998, 23: 55-62.

14.Terata R, Nakashima K, Obara M, Kubota M. Characterization of enamel and dentin surfaces after removal of temporary cement--effect of temporary cement on tensile bond strength of resin luting cement. Dent Mater J, 1994, 13: 14854.

15.Woody TL, Davis RD. The effect of eugenolcontaining and eugenol-free temporary cements on microleakage in resin bonded restorations. Oper Dent 1992, 17: 175-80.
16.Olin PS, Rudney JD, Hill EM. Retentive strength of six temporary dental cements. Quintessence Int, 1990, 21: 197-200.

17.Lepe X, Bales DJ, Johnson GH. Retention of provisional crowns fabricated from two materials with the use of four temporary cements. J Prosthet Dent1999, 81: 469-75.

18. Kim Y, Yamashita J, Shotwell JL, Chong KH, Wang $\mathrm{HL}$. The comparison of provisional luting agents and abutment surface roughness on the retention of provisional implant-supported crowns. J Prosthet Dent 2006, 95: 450-5.

19.Ishikiriama $A$, Busato $A L$, de Lima Navarro MF, Mondelli J. Temporary cementation of acrylic resin and cast complete crowns. J Prosthet Dent 1984, 51: $637-41$.

\author{
Yazışma Adresi: \\ Dr. Alper ÖZDOĞAN \\ Atatürk Üniversitesi \\ Diş Hekimliği Fakültesi \\ Protetik Diş Tedavisi AD. \\ ERZURUM \\ TIf 5392018440 \\ e-mil: alprozdgn@gmail.com
}

